Karla Parsons ORCID iD: 0000-0003-4586-8703

\title{
Health Behavior Knowledge among Hispanic California Islanders: Evaluation of a Parental Educational Intervention
}

\author{
Running Head: Health Behavior Knowledge among Hispanic Parents \\ Karla Parsons, DNP, RN, FNP-BC, CCSN \\ Assistant Professor, School of Nursing \\ California State University, Fullerton \\ kparsons@fullerton.edu \\ $657-278-8520$ \\ $310-801-5830$ (c) \\ Elaine M. Rutkowski, PhD, RN, CNS, PHN \\ Professor, School of Nursing \\ California State University, Fullerton \\ erutkowski@fullerton.edu \\ Ofir Turel, PhD \\ Professor, Information Systems and Decision Sciences \\ California State University, Fullerton \\ oturel@fullerton.edu \\ There was no outside grant funding source for this original work. \\ Conflict of interest: None
}

This is the author manuscript accepted for publication and undergone full peer review but has not been through the copyediting, typesetting, pagination and proofreading process, which may lead to differences between this version and the Version of Record. Please cite this article as doi: 10.1111/jspn.12235.

This article is protected by copyright. All rights reserved. 


\begin{abstract}
Purpose: To evaluate the impact of a school nurse-led pilot parent-focused education program for healthy eating and physical activity to reduce childhood obesity.

Design and Methods: A quasi-experimental intervention design was used to assess the knowledge of 11 Hispanic mothers regarding healthy food choices and physical activity over a period of 1 year.

Results: There was improvement in parental knowledge domains. Children’s Body Mass Index (BMI) stabilized at the one-year follow-up in the intervention group, while the BMI increased in non- intervention group. Outcomes included improvement in parental health knowledge and children’s BMI.
\end{abstract}

Practice Implications: Pediatric and school nurses have a powerful role in preventive education. Knowledge gained by identifying the benefits of healthy food choices and physical activity for Hispanic mothers of obese children can be transformed into lifestyle changes for their children's weight control that begin in the home.

Keywords: obesity, childhood, parents, knowledge, Hispanic, rural

What is currently known is that parents, particularly mothers, have a primary role in how their children adopt healthy behaviors around food choices and activity levels in the home, but a gap exists in the literature regarding school nurse- led Hispanic parentfocused health education in a rural setting

This article adds value by using a tailored and leveled educational approach to increase parental knowledge related to healthy meal planning and activity levels.

This article is protected by copyright. All rights reserved. 
The epidemic of childhood obesity affects nearly 17\% of American children (Ogden, Carroll, Kit, \& Flegal, 2014), which is triple the percentage from past generations (World Health Organization, 2012). The impact of childhood obesity has been linked to a range of physical and psychological health conditions including diabetes, depression, reduced quality of life, poor academic outcomes and reduced life expectancy (Carey, Singh, Brown, \& Wilkinson, 2015; Sahoo et al., 2015; Schwimmer, 2003). Given the limited control children have over their home environment, it may not be surprising that family characteristics such as parental control, health beliefs, and attitudes are identified as key risk factors for childhood obesity (De Goede, Branje, Delsing, \& Meeus, 2009; Mielke, Parsons, \& Greenberg, 2014).

The burden of the childhood obesity epidemic is not borne equally across the population, as the prevalence estimates vary by gender, age, and ethnicity. A recent study noted that approximately 38.2\% of Hispanic children ages 2-9 were overweight or obese compared to $29.3 \%$ of white children of the same age (Ogden et al., 2010).

The socioeconomic status of a child's family has been correlated to an increased risk of childhood obesity as children, especially females, from poorer families are affected by lower parental education and household income (Baidal et al., 2016; Kitsantas \& Gaffney, 2010). Significantly higher odds of obesity are found in rural settings (Johnson \& Johnson, 2015) that may be explained by limited educational community resources (Foster \& Hale, 2015; May, Freedman, Sherry, \& Blanck, 2013). The literature shows that Hispanic mothers believe that "big and strong” children are healthy and thereby promote high-calorie meals (Ayala et al., 2007; Hughes, Power, Fisher, Mueller, This article is protected by copyright. All rights reserved. 
\& Nicklas, 2005; Lindsay, Sussner, Greaney, \& Peterson, 2010; Tschann et al., 2013). Furthermore, Tschann, J.M, et al. (2013) found that among Mexican mothers, positive involvement in their child's eating habits through food preparation and modeling good food choices along with monitoring the child's intake by limiting consumption of highcalorie foods, was associated with lower weight. The literature found point to the powerful role of parents and families in teaching healthy interpersonal skills and habits though their own role modeling.

Parental education as a primary intervention for changing behaviors in children is supported by previous research with brief parent management trainings producing significant gains in improving a sense of competence in the parents of young children ((Barlow et al., 2015); Colalillo \& Johnston, 2016; Cotter, Bacallao, Smokowski, \& Robertson, 2013; Kamik \& Kanekar, 2012). A meta-analysis of school-based obesity educational programs by Sobol-Goldberg, Rabinowitz, and Gross (2013) found that parental involvement was associated with greater success.

Registered nurses who work in clinical and community settings, such as school nurses, are primary health educators and have tremendous potential to identify, prevent and educate parents of overweight and obese children and adolescents (Broussard, 2004). School nurses, by the nature of their positon, develop relationships with students and their parents. This unique relationship works positively to implement interventions which include both student and parent. Interventions to advance the well-being, health, academic success and lifelong achievement of children by means of promoting community health activities are described in position statements by the National 
Association of School Nurses (NASN) in their Framework for $21^{\text {st }}$ Century Nursing Practice (2016) and the American Academy of Pediatrics, (2016). The Framework takes the students and family members, along with the community into consideration with key foundational principles that include community/public health. Unfortunately, relatively few studies have investigated school-based obesity prevention services targeting parents. In an integrative review of the literature, researchers found 17 studies in the category of school-based community/public health principles, but none of these studies included parental education of obese children (Best, Oppewal, \& Travers, 2017).

The community of Avalon, California, is located on a remote island off the coast of Southern California with a population of 3,127 year-round residents, of whom $71 \%$ are Hispanic (Avalon, 2016). The city faces many of the same problems as larger urban settings, including increasing tax bases for infrastructure repairs, community services and recreation. Additionally, Avalon residents experience severe barriers in accessing health services due to the island's geographical isolation from the mainland.

The most recent census report (U.S. Census Bureau, 2010) revealed a population in Avalon with a high risk of obesity due to both the demographic and socioeconomic characteristics of the island's year-round residents. As part of the island medical center's commitment to public health and prevention services, recommendations by the U.S. Preventive Services Task Force (2014) were examined and found to support the need for behavioral interventions for obese children and adolescents. In 2015, the island's medical center conducted a BMI review of all patients who were seen in the outpatient clinic for the same year and found more than 38\% of children seen were “overweight” and 5\% This article is protected by copyright. All rights reserved. 
were “obese” (Centers for Disease Control and Prevention, 2017), with the Hispanic children even higher at 52\%. The medical center entered into a collaborative project with the local school to evaluate a pilot study as a prevention service to parents of obese children. Using Albert Bandura’s (1982) Social Cognitive theory, there is the expectation that one can master a situation with a positive outcome. This study realized the factors that influence results of behavior change also include the environment and personal factors. The education provided to the participants promoted skill building with competencies in gaining knowledge relating to meal planning and preparation, the importance of physical activity and the of screen time. It is plausible that gained knowledge would result in change with their children’s BMI one year after the education.

Parents, especially mothers, play an important modeling role in protecting their children from obesity through involving their children in shopping, cooking, and physical activities (Baidal et al., 2016). Many island family households are managed by parents who hold multiple jobs to maintain financial viability. The impact of this busy lifestyle for the islanders has a direct impact on parenting activities, such as food preparation and after school monitoring of physical activity. As demonstrated in Bronfenbrenner's Ecological Systems Theory Model, the child's activities are directly informed by those of their parents as well as the environment's impact upon the family (Bronfenbrenner, U., 1977). While interventions directly targeting children and adolescents through diet, physical activity, and behavioral counseling are often commonly used to address childhood obesity, it is also important to understand the impact of parental knowledge on modifying these behaviors related to their children’s health (Rutkowski \& Connelly,

This article is protected by copyright. All rights reserved. 
2012).

\section{Problem Statement}

There is a scarcity of culturally specific interventions for educating a Hispanic island community regarding the lifestyle changes needed to modify obesity in lifestyle changes to modify obesity in children.

\section{Purpose}

The purpose of this project was to evaluate the efficacy of a four-week health pilot intervention with specific aims targeting parents to improve parental knowledge related to healthy eating, physical activity, and children’s screen/TV time behaviors by identifying changes that occurred at baseline (T1) and again after 90 days (T2) by answering the same questionnaire (National Heart Lung and Blood Institute \& National Institutes of Health, 2007a, 2007b). The children of the intervention group had Body Mass Index values that were recorded and compared at both baseline (T1) and one-year post-intervention (T3), as were the children from the non-intervention group of parents for both baseline and one year points in time (T1 and T3).

\section{Methods}

This program evaluation was approved by the university institutional review board. The island's medical center and school district provided approval for the program to be evaluated.For this intervention, the authors chose the We Can! Energize our Families curriculum, which targets parents of children ages 8 - 13 (National Heart, Lung and Blood Institute (NHLBI), 2013). Specific educational modules included in the We Can! Energize our Families program were presented over a period of four weeks (i.e., 
improving healthy food choices and becoming more physically active and reducing screen time) to explore their impact on participants' knowledge measured at two timepoints: baseline and 90 days

As a preliminary study using the curriculum, children of the parents in the education program were weighed and measured for body mass index (BMI) at baseline (T1) and one-year post-intervention (T3). A non-intervention group of overweight students of the same age range, ethnicity, parental education and similar demographic properties were selected and their BMIs were calculated at baseline (T1) and one-year post-intervention (T3).

\section{Setting}

The education took place in Avalon at the local public school library. The city's school is a kindergarten to $12^{\text {th }}$ grade campus that serves 700 children, of which $74.6 \%$ are Hispanic or Latino, Long Beach Unified School District, (2017).

\section{Recruitment}

Eligible participants for this purposive sampling (parents of overweight children from the age of $8-13$ living on the island) were identified via records collected from the local public school in coordination with the island's medical center in January 2015. A total of 60 eligible parents were recruited via English and Spanish letters circulated by a Spanish-speaking community service worker at the Medical Center and a series of follow-up phone calls. Both mother and father or caregiver were invited to participate.

This article is protected by copyright. All rights reserved. 


\section{Participants}

A total of 12 mothers provided written consent from the original 60 to participate along with proper assent from the children to have their BMI recorded before and one year after the intervention. When a follow up telephone survey was conducted prior to the first session, 48 parents were very interested in participating, but could not commit to the four sessions; either due to work schedules or other commitments. The remaining 12 mothers, who were all of Hispanic origin, arrived for the first program session in March 2015, and 11 provided data at both the baseline (T1) and 90 day’s (T2) post-test, as one family left the island and was not available to complete the one-year follow-up. For the non-intervention group, children were selected using school records during mandatory

screening done on $5^{\text {th }}$ through $8^{\text {th }}$ grade female children, recorded the previous year using the same age range, $\mathrm{BMI}>85^{\text {th }}$ percentile and of the same Hispanic ethnic origin. Overall, 23 children met the criteria, and 11 were randomly chosen from the list in even numbers to fill the non-intervention group representative of the population of the intervention group and to match the number. Parents of these children gave their consent for the measurements, and all children gave verbal assent. All children in both samples were female. Demographic information was also measured (see Table 1).

Table 1 near here.

\section{Materials/Curriculum}

The We Can! Energize our Families curriculum is largely focused on high impact teaching practices to engage and motivate participants while providing statistics and information about obesity and food misconceptions (National Heart, Lung and Blood

This article is protected by copyright. All rights reserved. 
Institute (NHLBI), 2013). High impact teaching involves meaningful interaction to foster learning outside of the "classroom” and includes dynamics of support and feedback. The program was delivered by a board- certified family nurse practitioner who is also a certified school nurse and was assisted as a bilingual translator. Each of the four weekly modules built upon the content from previous weeks.

The first session offered an introduction to the curriculum and an agenda. The power point slides offered participate involvement, such as identifying myths vs facts on topics relating to meal preparation, calories consumed, label reading as examples. At the end of each lesson, participants were encouraged to practice the new nutritional and physical activity choices for their families over the course of the following week. Participants then provided feedback to the group about their experiences in trying the new activities at the lesson the following week. Incentives were available to encourage group sharing; participants were able to select a take-home item from a gift table with prepackaged fresh vegetables and fruit. The 90- minute lessons included a pre-designed PowerPoint presentation from the We Can! Energize our Families curriculum that was also translated into Spanish. Healthy meal preparation techniques were shared, such as reducing fat intake by baking rather than frying foods or using olive oil in place of lard.

Activities that included the family were emphasized, as was participation in community sports teams, riding bicycles, walking, swimming, running and hiking, using the islands' unique features of readily available and safe venues. A 10 to 15- minute breakout period took place each session for physical activity with the popular Latino 
exercise called Zumba. Handouts from the lesson were provided in English and Spanish each week.

\section{Measurements}

The research team selected three questions from each knowledge domain of the We Can! Energize our Families parent questionnaire, a research-validated tool used by the National Institute of Health (National Heart Lung and Blood Institute \& National Institutes of Health, 2007a, 2007b). The questionnaires were given to the intervention group of parents in both English and Spanish. The survey consisted of 5 demographic questions and 15 questions covering five domains: energy balance, portion size, healthy eating, physical activity, and screen time (see Table 2). All questions were answered with "True” or "False”. Correct answers were coded as 1 and incorrect as 0; thus, knowledge in a domain ranged from 0 to 3 , where 0 meant no knowledge or fully incorrect knowledge and 3 meant fully correct knowledge.

Table 2 near here.

\section{Procedures}

The selected questions from the We Can! Energize our Families parent questionnaire were administered at two time-points: pre-intervention or baseline (T1) and 90 day’s post-intervention (T2) (see Table 3).

Table 3 near here.

BMI was recorded at school for the children whose parents participated in the program with calculations based on anthropometric measures (height and weight) taken by the same school nurse using the Body Mass Index (BMI) Percentile Calculator for

This article is protected by copyright. All rights reserved. 
Children (https://nccd.cdc.gov/dnpabmi/calculator.aspx). The scale used was a Detecto 399 model physician's scale with a weight capacity of 400 pounds with a height rod that measures 30 - 78 inches. Weight and height was measured without shoes or heavy overclothing. The diecast beam balance was reset before each weight was taken. These measurements were calculated at two time-points: baseline (T1) and 12 month’s (T3) post-intervention to best capture the progression of weight change. The non-intervention students BMI were calculated using captured height and weights taken and posted in the child's health record by the same school nurse using the same measurement protocol.

\section{Data Analysis}

Descriptive statistics using SPSS 24.0, (IBM Corp, 2016). were used to describe the sample and compare the groups and the knowledge domain scores. Paired-sample ttests were performed on pre-intervention and post-intervention knowledge scores of the participants. The level of significance for the analyses was set at 0.05 .

\section{Results}

\section{Participant Description}

Parental participants were exclusively Hispanic mothers of obese children and were either monolingual ( $\mathrm{n}=8$, Spanish) or bilingual ( $\mathrm{n}=3$, Spanish/English). Most had earned a high school or GED diploma and came predominantly from large households (on average, more than two adults and more than two children). In the non-intervention group, the children belonged to the same grades with comparable ages and educational levels of the mothers (Table 4).

Table 4 near here.

This article is protected by copyright. All rights reserved. 


\section{Impact of the We Can! Program on Knowledge}

The We Can! Energize our Families program led to increased knowledge in the parents. As shown in Table 3, scores on two knowledge domains increased, with "portion size knowledge” reaching significance ( $p=0.01$ ). Total knowledge improved but was not statistically significant $(p=0.07)$. Energy balance, physical activity and screen time knowledge domains did not improve at 90 days post-intervention.

To measure BMI changes in the intervention group, the pre-intervention BMI (T1) $(\mathrm{M}=32.63, \mathrm{SD}=5.68)$ was compared to the one-year (T3) post-intervention BMI $(M=32.73 . S D=5.98)$ using a paired-sample t-test. The difference was not significant $(\mathrm{p}<0.91)$. It was hence concluded that while knowledge in portion size and healthy eating improved, it was not enough to influence BMI changes one-year post-intervention.

Next, we tested the same progression in the non-intervention group. Their T1 BMI ( $\mathrm{M}=31.95, \mathrm{SD}=6.08)$ was compared to the one-year follow-up BMI at $\mathrm{T} 3$ $(\mathrm{M}=35.03 . \mathrm{SD}=5.45)$ using a paired-sample t-test. The $\mathrm{T} 3$ one-year post-intervention BMI in the non-intervention group was significantly higher than the T1 BMI (difference $=3.08, \mathrm{p}<0.003$ ). Thus, it seems that while the intervention did not significantly reduce BMI in the intervention group, the BMI levels were maintained. In contrast, BMI significantly increased over the one-year period in the non-intervention group in which parents did not receive the education. The change in BMI (1year postintervention minus initial BMI) was compared between the intervention and nonintervention groups. In the intervention group, it was $\mathrm{M}=0.09, \mathrm{SD}=2.38$; in the nonintervention group, it was $\mathrm{M}=3.08, \mathrm{SD}=2.68$. This difference was statistically significant

This article is protected by copyright. All rights reserved. 
$(\mathrm{p}<0.023)$. These findings indicate that the increase in BMI was much smaller in the intervention group than in the non- intervention group.

\section{Discussion}

Improvements were potentially realized in several areas. The parents’ relatively low baseline knowledge appears to have improved with the intervention. The method of dispelling nutritional "myths" by replacing them with nutritional facts underscored the importance of interventions targeting parental knowledge when working in rural Hispanic populations. This parent-focused intervention showed a significant improvement in portion size knowledge and substantial improvement in overall knowledge. Although the results were not statistically significant overall, the findings could be used by clinicians to address parental knowledge to assist in the goal in stabilizing children’s BMI measurements. The knowledge related to physical activity and screen time did not change significantly over the course of the intervention. Although there were no fathers present for the education, most mothers stated that their husbands "work late" or "have more than one job”.

During the four weekly sessions, mothers reported that they were motivated to learn and translate this knowledge into healthy food selection and preparation. In an adult atmosphere, the mother's openly shared concerns without the influence of their child's presence. Many reported that they were raised believing that 'big' children meant healthy children and not necessarily that the food should be healthy but that the food was available. The mothers were eager to share what they were changing and the responses of their children. One mother used smaller plates for meals as recommended in the program

This article is protected by copyright. All rights reserved. 
materials, while another mother started making a smoothie with protein powder, berries, and low fat milk in place of sugary cereal for breakfast. These anecdotes demonstrate the utility of this We Can! Energize our Families curriculum for use with rural Hispanic populations, as the curriculum was readily adaptable to this population.

The findings of this study support the current literature on the importance of parental education and self-efficacy in contributing to the success of a community childhood-obesity educational program (Karnik \& Kanekar, 2012; Rutkowski \& Connelly, 2012).

\section{Limitations}

The data were based on self-reporting. Although the two samples included the same age ranges, the parental education were not identical, which may further influence the findings through self-selection bias. Furthermore, the data were based on a limited sample size and single gender participants, and as a result, the findings are not generalizable. The We Can! parent questionnaire was used with parents whose demographics reflected similar ethnicity but were of a lower socioeconomic status and educational level than that of the Catalina Island group.

Although 12 parents originally showed interest in committing to the four-week program and 11 parents completed the program, many parents expressed interest but could not participate due to the timing and commitment of completing the four classes. Childcare was not provided, which may have impacted the parents' decisions to enroll in this study. A budget that encompasses staff time for planning, responding and educating the parents should also include incentives that are not donated. The program was well

This article is protected by copyright. All rights reserved. 
received by community agencies who were supportive in sponsoring with incentives, thus making it a shared collaborative community partnership effort.

Given the small number of participants in this program, the improvements across the knowledge domains and BMI stabilization, or in the shift from obese to overweight, in the intervention group compared to increases in the non-intervention group support the assertion that these changes are reflective of changes in lifestyle patterns due to overall parental knowledge. Ultimately, these data revealed a population with relatively low obesity-related knowledge and related health behaviors who benefitted from a shortduration intervention.

Further longitudinal research is needed to determine whether these findings hold in different and larger samples to extend the validity, reliability and generalizability of our findings.

\section{Conclusion}

Because childhood obesity is increasing at a rapid rate, pediatric nurses, in particular school nurses, are in a natural position to provide preventive education to help mediate childhood obesity (Quelly, 2017). In addition, pediatric and school nurses are trusted professionals with direct access to children and families, American Nurses Association (2017). The We Can! Energize our Families program is convenient for facilitation with its scripted weekly plan allowing for the educators to come from a variety of nursing and public health education backgrounds.

Educating parents of obese children on behavior and lifestyle changes is the foundation for obesity management. The program provides flexibility and adaptability to 
the facilitator, including community involvement and program activities that match the needs of the Hispanic population. While it appears a challenge for parents to maintain the healthy eating and exercise behaviors during the post-intervention year, the principles of these concepts theoretically remain for parents to re-implement in the future.

Empowering parents in their own community with information that is easily understood and applicable to real life can foster attitudes that support the adoption of healthier behavior patterns. These patterns can not only help to change obesity rates but also have a generational effect.

\section{References}

American Community Survey- Census Bureau. http://www.census.gov/programssurveys/acs

American Academy of Pediatrics. (2016). Role of the School Nurse in Providing School Health Services. Council on School Health. Pediatrics, May 2016, e20160852. doi:10.1542/peds.2016-0852

American Nurses Association. (2017). Nurses rank\# 1 most trusted profession for 15th year in a row. Retrieved from https://www.nursingworld.org

Avalon, Ca. (2016). About Avalon. Retrieved from http://www.citydata.com/city/Avalon-California.html

Ayala, G. X., Baquero, B., Arredondo, E. M., Campbell, N., Larios, S., \& Elder, J. P. (2007). Association between family variables and Mexican American children’s dietary behaviors. Journal of Nutrition Education and Behavior, 39(2), 62-69. doi: 1016/j.jneb.2006.08.025

Baidal, J. A., Locks, L. M., Cheng, E. R., Blake-Lamb, T. L., Perkins, M. E., \& Taveras,

This article is protected by copyright. All rights reserved. 
E. M. (2016). Risk factors for childhood obesity in the first 1,000 days. American Journal of Preventive Medicine, 50(6), 761-779. doi:

10.1016/j.amepre.2015.11.012

Bandura, A. (1977). Self-efficacy: Toward a unifying theory of behavioral change. Psychological Review, 84(2), 191-215. http://dx.doi.org.libproxy.fullerton.edu/10.1037/0033-295X.84.2.191

Barlow, J., Smailagic, N., Huband, N., Roloff, V., \& Bennett, C. (2000). Groupbased parent training programmes for improving parental psychosocial health. Cochrane Developmental, Psychosocial and Learning Problems Group,2015(4), CD010534.

Best, N. C., Oppewal, S., \& Travers, D. (2017). Exploring school nurse interventions and health and education outcomes: An integrative review. The Journal of School Nursing, 34(1), 14-27. doi: 10.1177/1059840517745359

Body Mass Index (BMI). Percentile calculator for children. Retrieved from https://nccd.cdc.gov/dnpabmi/calculator.aspx

Bronfenbrenner, U. (1977). Toward an experimental ecology of human development. American Psychologist, 32(7), 513-531.http://dx.doi.org/10.1037/0003066X.32.7.513

Broussard, L. (2004). School nursing: Not just band-aids any more! Journal for Specialists in Pediatric Nursing, 9(3), 77-83. doi: 10.1111/j.15475069.2004.00077.x

Carey, F. R., Singh, G. K., Brown, H. S., \& Wilkinson, A. V. (2015). Educational outcomes associated with childhood obesity in the United States: Cross-sectional

This article is protected by copyright. All rights reserved. 
results from the 2011-2012 National survey of children's health. International Journal of Behavioral Nutrition and Physical Activity, 12(Suppl 1), S3. doi: 10.1186/1479-5868-12-s1-s3

Centers for Disease Control and Prevention. (2017). Over-weight and obesity. Retrieved from http://www.cdc.gov/obesity/data/childhood.html

Colalillo, S., \& Johnston, C. (2016). Parenting cognition and affective outcomes following parent management training: A systematic review. Clinical Child and Family Psychology Review, 19(3), 216-235. doi: 1007/s10567-016-0208-z

Cotter, K. L., Bacallao, M., Smokowski, P. R., \& Robertson, C. I. B. (2013). Parenting interventions implementation science: How delivery format impacts the parenting wisely program. Research on Social Work Practice, 23(6), 639-650. doi: $10.1177 / 1049731513490811$

De Goede, I., Branje, S., Delsing, M., \& Meeus, W. (2009). Linkages over time between adolescents' relationships with parents and friends. Journal of Youth Adolescence, 38, 1304-1315. doi: 10.1007/s10964-009-9403-2

Foster, B. A., \& Hale, D. (2015). Perceptions of weight and health practices in hispanic children: A mixed-methods study. International Journal of Pediatrics, 2015, 6. doi: 10.1155/2015/761515

Foster, J. S., Contreras, D., Gold, A., Keim, A., Oscarson, R., Peters, P., Procter, S., Remig, V., Smathers, C. \& Mobley, A. R. (2015). Evaluation of nutrition and physical activity policies and practices in child care centers within rural communities. Childhood Obesity, Vol. 11, No.5. https://doi-org.libproxy.fullerton.edu/10.1089/chi.2015.0030

This article is protected by copyright. All rights reserved. 
Hughes, S. O., Power, T. G., Fisher, J. O., Mueller, S., \& Nicklas, T. A. (2005).

Revisiting a neglected construct: Parenting styles in a child-feeding context. Appetite, 44(1), 83-92. doi: 10.1016/j.appet.2004.08.007

IBM Corp. Released 2016. (2016). IBM SPSS statistics for windows, Version 24.0. Armonk, NY: IBM Corp.

Johnson, J. A., \& Johnson, A. M. (2015). Urban-rural differences in childhood and adolescent obesity in the United States: A systematic review and meta-analysis. Childhood Obesity, 11(3), 233-241. doi: 10.1089/chi.2014.0085

Karnik, S., \& Kanekar, A. (2012). Childhood obesity: A global public health crisis. International Journal of Preventative Medicine, 3(1), 1-7.

Kitsantas, P., \& Gaffney, K. F. (2010). Risk profiles for overweight/obesity among preschoolers. Early Human Development, 86(9), 563-568. doi:

10.1016/j.earlhumdev.2010.07.006

Lindsay, A. C., Sussner, K. M., Greaney, M. L., \& Peterson K. E. (2010). Latina mothers' beliefs and practices related to weight status, feeding, and the development of child overweight. Public Health Nursing, 28(2), 107-118. doi: 10.1111/j.15251446.2010.00906.x

Long Beach Unified School District. (2017). Student accountability report card. Retrieved from https://www.sarconline.org/Sarc/About/19647251930411?year=2016-17

May, A. L., Freedman, D., Sherry, B., \& Blanck, H. M. (2013). Obesity - United States, 1999-2010. Morbidity and Mortality Weekly Report, 62(3), 120-128.

This article is protected by copyright. All rights reserved. 
Mielke, R., Parsons, K., \& Greenberg, C. (2014). Puberty through early adulthood. In E. Oshansky (Ed.), Women's health and wellness across the lifespan (pp. 29-67). Philadelphia, PA: Wolters Kluwer.

National Association of School Nurses. (2016a). Research priorities. Retrieved from https://www.nasn.org/research/research-priorities

National Association of School Nurses. (2016b). The role of the 21st-century school nurse. NASN School Nurse, 32(1), 56-58. doi: 10.1177/1942602x16680171

National Association of School Nurses. (2017). Students with chronic health conditions: The role of the school nurse (Position Statement). Silver Spring, MD: National Association of School Nurses. Retrieved from https://www.nasn.org/advocacy/professional-practice-documents/positionstatements

National Heart Lung and Blood Institute \& National Institutes of Health. (2007a). We can! program summary. Retrieved from https://www.nhlbi.nih.gov/health/educational/wecan/downloads/progsummary.pdf National Heart Lung and Blood Institute \& National Institutes of Health. (2007b). We can! parent curriculum evaluation questionnaire. Retrieved from www.nhlbl.nih.gov/health/educational/wecan/downloads/parent-questionnaire.pdf

Ogden, C. L., Carroll, M. D., Kit, B. K., \& Flegal, K. M. (2014). Prevalence of childhood and adult obesity in the United States, 2011-2012. JAMA, 311(8), 806-814. doi: 10.1001/jama.2014.732

Quelly, S. B. (2017). Characteristics associated with school nurse childhood obesity

This article is protected by copyright. All rights reserved. 
prevention practices. Pediatric Nursing, 43(4), 193-199.

Rutkowski, E. M., \& Connelly, C. D. (2012). Self-efficacy and physical activity in adolescent and parent dyads. Journal for Specialists in Pediatric Nursing, 17(1), 51-60. doi: 10.1111/j.1744-6155.2011.00314.x

Sahoo, K., Sahoo, B., Choudhury, A., Sufi, N., Kumar, R., \& Bhadoria, A. (2015). Childhood obesity: Causes and consequences. Journal of Family Medicine and Primary Care, 4(2), 187-192. doi: 4103/2249-4863.154628

Schwimmer, J. B. (2003). Health-related quality of life of severely obese children and adolescents. JAMA, 289(14), 1813-1819. doi: 10.1001/jama.289.14.1813

Sobol-Goldberg, S., Rabinowitz, J., \& Gross, R. (2013). School-based obesity prevention programs: A meta-analysis of randomized controlled trials. Obesity, 21(12), 24222428. doi: 10.1002/oby.20515

Tschann, J. M., Gregorich, S. E., Penilla, C., Pasch, L. A., de Groat, C. L., Flores, E., .. . Butte, N. F. (2013). Parental feeding practices in Mexican American families: Initial test of an expanded measure. International Journal of Behavioral Nutrition and Physical Activity, 10(1), 6. doi: 10.1186/1479-5868-10-6

U.S. Census Bureau. (2010). Profile of general population and housing characteristics: 2010. 2010 demographic profile data. Retrieved from http:/factfinder.census.gov/faces/tableservices/jsf/pages/productview.xhtml?src= CF

U.S. Preventive Services Task Force. (2014). Obesity in children and adolescents screening. Retrieved from

This article is protected by copyright. All rights reserved. 
http://www.uspreventiveservicestaskforce.org/Page/Topic/recommendationsummary/obesity-in-children-and-adolescents-screening

World Health Organization. (2012). Childhood overweight and obesity. Retrieved from http://www.who.int/dietphysicalactivity/childhood/en/

\section{Tables}

\section{Table 1.}

Demographic Characteristics of the Pilot and Control Sample $(\mathrm{n}=11)$

\begin{tabular}{|c|c|c|c|c|c|c|}
\hline \multirow[b]{2}{*}{ Demographic } & \multicolumn{2}{|c|}{$\begin{array}{l}\text { Intervention Group } \\
\qquad(\mathrm{n}=11)\end{array}$} & \multicolumn{2}{|c|}{$\begin{array}{l}\text { Non -Intervention } \\
\text { Group } \\
(\mathrm{n}=11)\end{array}$} & \multicolumn{2}{|c|}{$\begin{array}{l}\text { Island Population } \\
\qquad(\mathrm{n}=3,678) *\end{array}$} \\
\hline & $\begin{array}{r}\text { Mean or } \\
\text { Median }\end{array}$ & n (\%) & $\begin{array}{r}\text { Mean or } \\
\text { Median }\end{array}$ & n (\%) & $\begin{array}{l}\text { Mean or } \\
\text { Median }\end{array}$ & n (\%) \\
\hline Age, Median & 40.0 & & 40.45 & & 44.5 & \\
\hline Hispanic & 11 & 100 & 11 & 100 & & 2155 (58.6) \\
\hline Male & & 0 & & 0 & & 1,559 (49.9) \\
\hline Female & & $11(100)$ & & $11(100)$ & & $1,568(50.1)$ \\
\hline Household Size, Mean & 5.36 & & 4.91 & & 3 & \\
\hline
\end{tabular}

This article is protected by copyright. All rights reserved. 
$<$ High School

High School Graduate

At Least Some College
$4(36.4)$

$6(54.5)$

$1(9.1)$
$5(45.5)$

$6(54.5)$

$47.7 \quad 1111(24.3)$

* American Community Survey (ACS) - Census Bureau http://www.census.gov/programs-surveys/acs
$606(26)$

$26.31,003(51.2)$

\section{Table 2.}

Descriptive Statistics for Intervention Participants and Non-intervention Participants

\begin{tabular}{lll}
\hline Participants & $\begin{array}{l}\text { Intervention Group } \\
(\mathrm{n}=11)\end{array}$ & $\begin{array}{l}\text { Non- Intervention } \\
\text { Group } \\
(\mathrm{n}=11)\end{array}$ \\
\hline & M SD & M SD \\
\hline Parent ages (baseline) & 40.004 .05 & 40.533 .92 \\
Child age (baseline) & 12.001 .36 & 11.541 .21 \\
BMI at baseline & 32.635 .68 & 31.956 .08 \\
BMI 1 year post & 32.735 .98 & 35.045 .45 \\
\hline
\end{tabular}

This article is protected by copyright. All rights reserved. 
Table 3.

Summary of “We Can” Questionnaire Outcomes

\begin{tabular}{|c|c|c|c|c|}
\hline \multirow[t]{2}{*}{$\begin{array}{l}\text { Knowledge } \\
\text { Domain }\end{array}$} & Questions & $\begin{array}{l}\text { Pre- } \\
\text { training } \\
\text { Score }\end{array}$ & $\begin{array}{l}\text { Post- } \\
\text { training } \\
\text { Score }\end{array}$ & $\begin{array}{l}\mathrm{p}- \\
\text { value }\end{array}$ \\
\hline & & M (SD) & M (SD) & \\
\hline $\begin{array}{l}\text { Energy } \\
\text { balance }\end{array}$ & $\begin{array}{l}\text { You can maintain a healthy weight just by making sure } \\
\text { that food intake (energy in) equals physical activity } \\
\text { (energy out) on most days } \\
\text { One effective way of losing weight is to burn more } \\
\text { energy than you take in } \\
\text { Being more active on one day cannot help balance } \\
\text { extra calories consumed on another day }\end{array}$ & $\begin{array}{l}2.18 \\
(0.60)\end{array}$ & $\begin{array}{l}2.09 \\
(0.54)\end{array}$ & 0.72 \\
\hline $\begin{array}{l}\text { Portion } \\
\text { size }\end{array}$ & $\begin{array}{l}\text { A serving size is the total amount of food a person is } \\
\text { served or chooses to eat at one time while a portion } \\
\text { size is a standard amount of food } \\
\text { Portion sizes of food have remained the same over the } \\
\text { years } \\
\text { When a person eats larger portions, more physical } \\
\text { activity will not prevent him/her from gaining weight }\end{array}$ & $\begin{array}{l}0.82 \\
(0.75)\end{array}$ & $\begin{array}{l}1.72 \\
(1.00)\end{array}$ & 0.01 \\
\hline $\begin{array}{l}\text { Healthy } \\
\text { eating }\end{array}$ & $\begin{array}{l}\text { Fried foods and baked goods should only be eaten } \\
\text { occasionally } \\
\text { Baking, broiling, boiling or microwaving are unhealthy } \\
\text { ways to cook } \\
\text { Removing the skin from poultry is a good way to } \\
\text { reduce the fat }\end{array}$ & $\begin{array}{l}2.18 \\
(0.75)\end{array}$ & $\begin{array}{l}2.55 \\
(0.68)\end{array}$ & 0.10 \\
\hline $\begin{array}{l}\text { Physical } \\
\text { activity }\end{array}$ & $\begin{array}{l}\text { Health experts say that children should spend at least } \\
\text { one hour each day in moderate to vigorous intensity } \\
\text { physical activity } \\
\text { Multiple short periods of exercise (e.g. four } 10 \text { minute } \\
\text { periods) are not as beneficial as a single long period } \\
\text { (e.g. } 40 \text { minutes) in terms of healthy weight } \\
\text { maintenance } \\
\text { It may be adequate for adults to spend just } 30 \text { minutes } \\
\text { each day engaged in moderate physical activity to be } \\
\text { physically fit }\end{array}$ & $\begin{array}{l}2.46 \\
(0.52)\end{array}$ & $\begin{array}{l}2.36 \\
(0.50)\end{array}$ & 0.59 \\
\hline $\begin{array}{l}\text { Screen } \\
\text { time }\end{array}$ & $\begin{array}{l}\text { Children who do not have television in their bedrooms } \\
\text { spend as much time watching television as children } \\
\text { who do have them in their bedrooms } \\
\text { People tend to eat less when they spend a lot of time } \\
\text { watching TV } \\
\text { Studies show that children in homes where rules on } \\
\text { watching TV are enforced spend less time watching TV }\end{array}$ & $\begin{array}{l}2.09 \\
(0.83)\end{array}$ & $\begin{array}{l}2.09 \\
(0.70)\end{array}$ & 1.00 \\
\hline
\end{tabular}

This article is protected by copyright. All rights reserved. 
than children in homes where such rules are not enforced

$\begin{array}{lllll}\text { Overall } & \text { All of the above } & 1.94 & 2.15 & 0.07 \\ \text { Knowledge } & & & (0.45)\end{array}$

Note. Paired t-tests were used to determine differences between scores at baseline and at 90 days.

Table 4. The Points in Time for Measurement

\begin{tabular}{lll}
\hline & Time & Measure \\
\hline T1 & 0 [baseline] & Baseline knowledge, Baseline BMI \\
T2 & 90 days & Knowledge [90 days post-intervention] \\
T3 & 1 year & BMI [1year post-intervention] \\
\hline
\end{tabular}

This article is protected by copyright. All rights reserved. 


\section{University Library}

\section{- M M I N E R VA A gateway to Melbourne's research publications}

Minerva Access is the Institutional Repository of The University of Melbourne

\section{Author/s:}

Parsons, K;Rutkowski, EM;Turel, O

Title:

Health behavior knowledge among Hispanic California islanders: Evaluation of a parental educational intervention

Date:

2019-01-01

Citation:

Parsons, K., Rutkowski, E. M. \& Turel, O. (2019). Health behavior knowledge among Hispanic California islanders: Evaluation of a parental educational intervention. JOURNAL FOR SPECIALISTS IN PEDIATRIC NURSING, 24 (1), https://doi.org/10.1111/jspn.12235.

Persistent Link:

http://hdl.handle.net/11343/285243 